\title{
Opinião de egressos sobre o curso de residência em gerência dos serviços de enfermagem
}

\section{Opinion of former residency students in nursing management}

\author{
Gisele Magnabosco우 Maria do Carmo Lourenço Haddad²; Marli Terezinha Oliveira \\ Vannuchi ${ }^{3}$; Mariana Angela Rossaneis ${ }^{4}$; Larissa Gutierrez de carvalho Silva ${ }^{5}$
}

\begin{abstract}
Resumo
Este estudo teve como objetivo verificar a opinião de egressos sobre a residência em Gerência dos Serviços de Enfermagem da Universidade Estadual de Londrina, identificando o quanto a pratica em serviço aliada a competências propostas e desenvolvidas durante o curso ampliaram a visão dos enfermeiros no gerenciamento das unidades onde atuam. Pesquisa descritiva, retrospectiva, de abordagem qualitativa, realizada por meio de entrevistas com egressos da primeira e segunda turma da Residência em Gerência dos Serviços de Enfermagem. Todos os entrevistados escolheram a residência devido à necessidade de fazerem um curso de especialização. $\mathrm{O}$ incentivo à pesquisa por meio da redação de artigos científicos motivou a busca por cursos de mestrado após o término da residência. A residência proporcionou segurança e experiência profissional embasando o enfermeiro no desenvolvimento de atividades científicas estimulando o aprimoramento profissional.
\end{abstract}

Palavras-chave: Educação em enfermagem. Educação de Pós-Graduação em enfermagem. Enfermagem.

\begin{abstract}
This study aimed to verify the opinion of former residency students about the Nursing Management Residency Program at Londrina State University, to identify the influence of practice allied to the competencies proposed and developed during this residency program over the nurses' view while managing nurse services they attend. Method: this is a descriptive and retrospective research with a qualitative approach. Interviews were conducted with former residency students from the first and second classes of the Nursing Management Residency Program. Results: all interviewees chose their respective residency program based on the necessity to specialize in that area. The incentive to research by writing scientific articles lead students to enroll in Master Degrees Programs. The Residency program provides security and professional expertise grounding the nurses with scientific knowledge contributing to professional improvement.
\end{abstract}

Keywords: Education Nursing. Education nursing graduate. Nursing.

\footnotetext{
${ }^{1}$ Enfermeira. Especialista em Gerência de Serviços de Enfermagem.

${ }^{2}$ Enfermeira. Doutora em Enfermagem. Docente do Departamento de Enfermagem da Universidade Estadual de Londrina.

${ }^{3}$ Enfermeira. Doutora em Enfermagem. Docente do Departamento de Enfermagem da Universidade Estadual de Londrina.

${ }^{4}$ Enfermeira. Mestre em Ciências. Doutoranda em Enfermagem na Universidade Estadual de Maringá.

${ }^{5}$ Enfermeira. Mestre em Enfermagem. Doutoranda em Ciências na Escola de Enfermagem de Ribeirão Preto. Docente do Departamento de Enfermagem da Universidade Estadual de Londrina.
} 


\section{Introdução}

Os modelos de formação dos profissionais da saúde reportam ao início do século XXI, quando se iniciou a reorganização dos serviços de saúde, onde as principais atuações baseiavam-se na promoção da saúde, prevenção e tratamento de agravos (SILVA; SENA, 2008). A recuperação da dimensão cuidadora e a busca da integralidade na atenção à saúde eram desafios colocados para a organização do cuidado no interior dos hospitais.

Acompanhando este processo, os cursos da área da saúde buscaram aprimorar e implementar em seus currículos os princípios do Sistema Único de Saúde (SUS) para formação de profissionais competentes, a fim de que estes sejam capacitados para assistir a população que usufrui desse sistema público, assim como buscar a melhor forma de gerenciar estes serviços. Portanto, o enfermeiro ao iniciar um programa de aprimoramento, traz expectativas em torno da sua qualificação, anseia por mudanças pessoais, além de contribuir para a instituição hospitalar (HADDAD, 2012; SIMONETTI et al., 2007).

A Universidade Estadual de Londrina (UEL) implantou em 2006 o Programa de Residência em Enfermagem com 12 vagas distribuídas nas áreas Neonatal, Saúde da Criança, Enfermagem Médicocirúrgica, Gerência dos Serviços de Enfermagem e em Centro Cirúrgico e Central de Materiais. Caracteriza-se como treinamento em serviço e possibilita ao enfermeiro recém-graduado o crescimento profissional através do aperfeiçoamento de habilidades técnicas e obtenção do título de especialista na área de escolha. Em 2008, o número de vagas foi ampliado para 24 devido aos bons resultados obtidos e por solicitação dos serviços (VANNUCHI; CAMPOS, 2007).

Segundo a resolução do Conselho Federal de Enfermagem (COFEN) no 259/2001 em seu artigo $2^{\circ}$, "a residência em enfermagem configura-se em modalidade de pós-graduação "Latu Sensu" destinada a enfermeiros, caracterizada por desenvolvimento das competências técnico-cientifica e ética, decorrentes do treinamento em serviço." (CONSELHO FEDERAL DE ENFERMAGEM, 2001).

Os residentes ocupam seus espaços nas intituições de saúde, sendo vistos como um grupo consolidado e reconhecido socialmente como prestador de assistência à saúde em diferentes campos de atuação, possui valores, ideias e suas próprias representações diante da profissão escolhida (SIMONETTI et al., 2007).

Esse tipo de capacitação eleva a qualidade da assistência no serviço de saúde e forma profissionais mais bem preparados para a prática profissional, com condições de atender os grandes centros onde a tecnologia exige maior conhecimento e especialização. É caracterizada por sua dedicação exclusiva e o residente entra em contato direto com os pacientes, acompanhando sua evolução e cumprindo atividades teorico-práticas. Possui rígido sistema de formação que pretende colocar enfermeiros mais preparados para o mercado de trabalho (PINHEIRO; ZEITOUNE, 2011).

A prática em serviço realizada por estudantes em hospitais tem papel fundamental na construção de gestores, em meio à complexidade dos sistemas de saúde, sendo de fundamental importância na construção de identidades profissionais e na produção do cuidado, considerando a busca por qualidade, integralidade, eficiência e controle de custos nos sistemas de saúde (FEUERWERKER; CECÍLIO, 2007).

O foco dos cursos de enfermagem está em preparar o profissional para atuar com competência e sabedoria em sua área. Pressupõe-se que o ensino aliado a prática em serviço possibilite ao profissional obter segurança e experiência em sua profissão. Em saúde, essa prática é primordial, uma vez que ao se lidar com pessoas doentes ou que necessitam de ajuda, é essencial que a experiência profissional aconteça de forma gradativa.

Para o estudante de enfermagem, a cobrança e a responsabilidade de ser um bom profissional exigem 
que em sua graduação a prática em serviço seja desenvolvida em setores onde o aluno atue junto à realidade da população conhecendo seus anseios e atentando-se a suas necessidades. Nesse sentido, os cursos de residência em enfermagem possibilitam ao estudante a prática junto aos serviços de saúde, fazendo com que o profissional, na maioria das vezes, recém-formado, conheça a realidade dos serviços, assumindo equipes em unidades de internação e resolvendo problemas cotidianos, sempre respaldados por profissionais dos setores e por docentes, além de atentar para questões gerenciais, tendo em vista os aspectos éticos e baseando-se nos princípios do SUS (HADDAD, 2012).

Em 2009, a residência em Gerencia dos Serviços de Enfermagem da UEL formou sua terceira turma, tendo como finalidade "[...] capacitar o enfermeiro a atuar na área de administração dos serviços de enfermagem, com vistas a analisar, intervir e modificar o quadro vigente, quando necessário, levando em conta a complexidade da organização." (VANNUCHI; CAMPOS, 2007, p. 360).

O curso tem duração de 24 meses, com carga horária semanal de 52 horas, divididas entre prática em serviço (42 horas) e aulas teóricas (10 horas) totalizando 5.010 horas. As aulas teóricas abordam assuntos de interesse geral e especifico de cada área, sendo dividida em Tronco Comum, onde residentes de todas as especialidades compartilham de um mesmo conteúdo, e em Tronco Específico, onde cada especialidade discute assuntos restritos a sua área. Ao longo dos dois anos do curso, o residente é estimulado a escrever artigos para publicação, e participação em eventos científicos, desenvolvendo temas que melhorem a prática assistencial dos serviços onde atua (UNIVERSIDADE ESTADUAL DE LONDRINA, 2014).

Muitas são as vantagens de um curso de residência planejado e bem estruturado. Além do preparo técnico científico, o residente adquire segurança profissional para o desenvolvimento das atividades práticas, se conscientiza da necessidade do aprendizado complementar elegendo prioridades, colabora com as orientações para a equipe de enfermagem proporcionando melhores condições de trabalho e elevando o padrão de atendimento institucional (SIMONETTI et al., 2007).

Contextualizando especificamente a residência em Gerencia dos Serviços de Enfermagem, no primeiro ano o estudante faz estágio por seis meses em um serviço de saúde de média complexidade e os outros seis meses em um serviço de saúde de alta complexidade (ou vice-versa), atentando-se para a visão gerencial do cuidado. Já no segundo ano, os campos de estágios são voltados ao gerenciamento hospitalar, envolvendo Recursos Humanos e Assessoria Técnica, Divisão de Treinamento e Pesquisa, Assessoria de Recursos Materiais, Chefia de Divisão de Enfermagem, Comissão de Controle de Infecção Hospitalar, Auditoria dos Serviços de Saúde, Divisão de Atendimento a Comunidade (foco na saúde do trabalhador). Ao final do curso, o residente retorna ao campo assistencial por três meses em unidades hospitalares. Além de participar das aulas do modulo de gerenciamento aos internos do curso de graduação em enfermagem.

Ao longo do processo, em cada campo de estágio o residente deve atingir os seguintes desempenhos: avaliar as necessidades de saúde do indivíduo, família e comunidade a partir da unidade de enfermagem; avaliar o processo de trabalho, a organização e infraestrutura dos serviços de enfermagem, utilizando como ferramenta o planejamento estratégico; planejar, executar e avaliar ações e cuidados de enfermagem; planejar, implementar e avaliar as ações de educação em saúde, Educação Permanente em Saúde e educação em serviço; desenvolver habilidade de comunicação, liderança, trabalho em equipe considerando a humanização e os aspectos éticos e legais; Elaborar, apresentar e encaminhar para publicação trabalhos científicos.

Nas aulas do tronco especifico, é utilizada uma metodologia ativa de aprendizagem, na qual o aluno, a partir da prática vivenciada no serviço, elabora 
relatos de experiência, que abordam temas e situações vivenciadas que atendam as competências propostas pela disciplina, contribuindo para o crescimento do conhecimento do grupo. Nesta propostametodológica, o docente é visto como um facilitador e o aluno busca o conhecimento por meio de investigações críticas, procurando responder questões que desafiam sua prática cotidiana (KIKUCHI; GUARIENTE, 2010).

A cada tema discutido, os residentes apontam os problemas vivenciados em seu campo de estágio seja ele hospital de média complexidade ou de alta complexidade, o grupo percebe que os problemas que cada um enfrenta são parecidos, e que em cada serviço acontecem da mesma forma. Esta metodologia propicia "[...] um embasamento ao residente para que no desempenho de suas funções se sinta motivado para o crescimento profissional, inovação gerencial e para o alcance de melhores resultados na instituição de saúde na qual ele venha a trabalhar" (VANNUCHI; CAMPOS, 2007, p. 360).

No intuito de demonstrar as atividades desenvolvidas durante a experiência como residente, e como esse processo contribui para a formação de um profissional competente e com uma visão global do processo gerencial, o objetivo deste estudo foi verificar a opinião dos egressos sobre a residência em gerência dos serviços de enfermagem da Universidade Estadual de Londrina.

\section{Método}

Trata-se de uma pesquisa descritiva, retrospectiva, de abordagem qualitativa, que foi realizada no segundo semestre de 2009. O principal objetivo da pesquisa descritiva é retratar precisamente as características dos indivíduos, situações ou grupos, e da frequência com que ocorrem determinados fenômenos (POLIT; BECK; HUNGLER, 2011).

A população do estudo foi constituída por enfermeiros egressos do curso de residência em Gerencia dos Serviços de Enfermagem nos anos de 2007 (primeira turma) e 2008 (segunda turma), os quais consentiram participar da pesquisa. $\mathrm{O}$ grupo vivenciou a implantação da residência em Gerencia dos Serviços de Enfermagem na UEL, totalizando sete enfermeiros.

Os dados foram coletados mediante questionário elaborado pela autora, contendo questões abertas, sendo posteriormente transcritos em formulário para análise de conteúdo, contendo as seguintes fases: préanalise, exploração do material e interpretação dos resultados (BARDIN, 2011). Assim, o conteúdo das entrevistas foi investigado em busca de recorrências de falas entre os respondentes, que posteriormente foram classificadas e categorizadas para, na análise, aproximar os conteúdos semelhantes e destacar os divergentes.

O estudo foi aprovado pelo Comitê de Ética em Pesquisa da UEL em 11 de setembro de 2009, sob parecer nº181/09 e seguiu a Resolução n 196/1996 do Conselho Nacional de Saúde.

\section{Resultados e Discussão}

A população estudada constitui-se de sete enfermeiros egressos. Estes profissionais participaram da implantação da residência na instituição, sendo que na primeira turma houve uma desistência durante o curso, o que explica haver apenas três enfermeiros no primeiro ano. Todos os entrevistados são do sexo feminino, com idades variando entre 24 e 27 anos, seis solteiras $(86 \%)$, dois $(30 \%)$ possuem filhos. Cinco (71\%) dos profissionais ingressaram na residência imediatamente após a conclusão da graduação.

Estes dados evidenciam a dificuldade encontrada pelos profissionais após a conclusão da graduação e a saída da universidade até a incorporação ao mercado de trabalho e a residência em enfermagem é vista como um facilitador deste processo, proporcionando respaldo docente e profissional ao recém-formado (MINETTO, 2008).

Após o término da residência, três dos egressos foram contratados em uma das instituições 
onde estagiaram e desenvolvem atividades de gerenciamento da assistência de enfermagem em serviços de alta complexidade; dois ingressaram em cursos de mestrado com dedicação exclusiva, um divide as atividades entre mestrado e trabalho, e apenas um encontrava-se desempregado. Para atender a demanda do mercado de trabalho que espera um profissional habilitado técnica e cientificamente, tanto os profissionais que seguiram carreira profissional como aqueles que partiram para a carreira acadêmica consideraram que a residência atingiu o objetivo proposto.

A análise de discurso foi categorizada em duas categorias, sendo: a escolha da especialidade e a contribuição do curso para a formação profissional.

\section{A escolha da especialidade}

Quando o profissional opta por um curso de pós-graduação é oportunizado a qualificação e a aquisição de conhecimentos específicos técnicocientíficos destacados na prática pela crítica e promoção de mudanças. Verificou-se que todos os entrevistados ingressaram na residência devido a necessidade de especialização exigida pelo atual mercado de trabalho:

Eu optei por fazer residência, porque já havia me formado há 2 anos e durante minha prática em serviço senti a necessidade de me especializar. (R1)

Escolhi a residência para me sentir mais segura e especializada para o mercado de trabalho. (R3)

A minha expectativa em relação à residência foi de possibilitar uma experiência profissional intensa, que é muito importante para um profissional recémformado, aliada a uma imersão no conhecimento teórico. Assim, a residência permite uma prática profissional reflexiva. (R4)

Penso que a residência é uma modalidade de pós graduação que capacita o profissional a atuar de uma forma mais crítico-reflexiva, com argumentos fundamentados. (R5)

Em relação à escolha pela especialidade "Gerência dos serviços de Enfermagem" verificou- se nos relatos a necessidade do profissional recém-formado possuir um maior embasamento administrativo e aprofundar conteúdos estudados durante a graduação. A teoria e a prática se relacionam a partir do aprimoramento do profissional e da necessidade exigida pela prática do cuidado, que necessita do saber para sua execução, resultando na valorização do conhecimento no cotidiano profissional (KIKUCHI; GUARIENTE, 2010).

O gerenciamento é a principal função do enfermeiro, portanto a especialidade traria maior embasamento teórico independente da área que eu iria trabalhar depois. (R2)

A escolha pela especialidade "Gerência em Serviços de Enfermagem" aconteceu por acreditar que o enfermeiro, independente do local em que estiver trabalhando, precisa gerenciar o cuidado de enfermagem da melhor forma possível para que o paciente tenha uma assistência de qualidade. (R4)

A escolha pela Gerência não foi para atuar na área administrativa da saúde, mas sim com o propósito de ampliar a visão do processo de trabalho, pois esta especialidade permite que tenhamos o conhecimento teórico-prático do gerenciamento das atividades desde o setor de internação até a alta gerência, de hospitais de diferentes complexidades. (R5)

$\mathrm{O}$ enfermeiro ao assumir a liderança de equipe que presta assistência aos usuários nos serviços de saúde necessita adquirir, desenvolver e aperfeiçoar competências gerenciais. Na maioria das vezes, busca complementar e qualificar a formação obtida na graduação por meio de cursos latu e stricto senso. A realização de curso de pós-graduação demostra o compromisso dos enfermeiros com a qualidade de seu desempenho profissional, o que é favorável para o alcance de bons resultados na sua atuação e melhoria dos indicadores de qualidade do serviço (SANTOS; CASTRO, 2010).

Em estudo com enfermeiros sobre desenvolvimento de competências gerenciais, os entrevistados citaram que a participação em programas de desenvolvimento pessoal e profissional, tais como cursos de aperfeiçoamento, pós-graduação (residência, especialização 
e mestrado), direcionados para a área de administração, economia e gestão em saúde foi essencial para o exercício do gerenciamento de serviços de enfermagem (ROTHBARTH; WOLFF; PERES, 2009).

\section{Contribuição do curso para a formação profissional}

Foi unânime entre as respostas dos entrevistados quanto ao crescimento profissional adquirido pelo enfermeiro durante o programa de residência, principalmente no que diz respeito aos campos de estágio, tanto gerenciais como assistenciais. A residência em enfermagem tem sido vista como uma importante forma de qualificação profissional, proporcionando ao enfermeiro recém-formado experiência e maturidade necessárias ao exercício profissional de forma gradual (MINETTO, 2008).

Contribuiu em muito. A residência me ajudou a olhar a prática de forma diferente. Contribuindo para que eu tivesse conhecimento e fundamentação na realização das minhas atividades diárias. (R1)

Ajudou a desenvolver habilidades como leitura de cenário, liderança, relacionamento interpessoal, além de dar embasamento teórico sobre vários assuntos utilizados no dia a dia do enfermeiro como gerenciamento de recursos humanos, recursos materiais, entre outros. (R2)

A residência me trouxe conhecimentos práticos e teóricos que não foram contemplados na minha graduação como técnicas de enfermagem, atendimento emergencial ao paciente, gerenciamento da unidade, maneiras de gerenciar conflitos, lidar com pessoas, maturidade profissional, possibilidade de estar à frente de equipes com constante discussão das situações vivenciadas com os tutores, busca pela leitura de artigos científicos, interesse na área científica. (R5)

A especialização nos moldes de residência prevê que o profissional de saúde possa unir a teoria de uma área específica, cada vez mais embasada em fundamentos científicos, ao que apreende e vivencia na prática do serviço em que se encontra inserido, por meio de treinamento contínuo na assistência supervisionada ao paciente. Tal capacitação tem a pretensão de formar um profissional com visão crítica da assistência a ser prestada, de forma a tornar o atendimento ao paciente mais eficiente (MANZI et al., 2013).

Profissionais de enfermagem qualificados e conscientes acerca do processo saúde/doença vigente no Brasil são agentes importantes para a elevação do nível de saúde da população e os cursos de residência em saúde possibilitam essa capacitação por meio de uma formação crítica e aprofundada (CARBOGIM et al., 2010).

A maioria dos enfermeiros que concluiu a residência conseguiu uma boa colocação no mercado de trabalho após o término do curso. Isso se deve ao desenvolvimento de habilidades teóricas e práticas realizadas durante a pós-graduação. Dos egressos que exercem atividades assistenciais após a residência, identificou-se nos relatos a importância da prática em serviços para a aquisição de experiência e segurança no desenvolvimento do trabalho.

A residência me ajudou muito, pois me trouxe embasamento para todas as atividades que tenho que realizar hoje na minha função como coordenadora. Além de ter me enriquecido em muito na prática, me tornando uma profissional experiente e segura. (R1)

[...] a residência abriu as portas para o mercado de trabalho e preparou-me notoriamente para enfrentálo. (R5)

A residência me deu a vivência em todos os segmentos de saúde que necessito (atenção primária, secundária e terciária) além de me proporcionar a estudar as grandes dificuldades que hoje o gerenciamento dos serviços de saúde enfrentam, me dando a segurança para exercer minha função de forma concreta e eficiente. (R6)

A residência abriu-me as portas para o meu primeiro emprego, onde pude aumentar minha prática assistencial como enfermeira. Meu segundo emprego foi em um Hospital também privado, que estava iniciando e após 3 meses recebi um cargo de Auditoria, onde consideram apenas minha experiência durante a residência. (R7)

Já, os residentes que optaram por atividades de aprimoramento em cursos de mestrado, os relatos em relação à residência evidenciam a importância 
das aulas teóricas e incentivo para pesquisa com a redação de artigos científicos, leitura e redação de sínteses dos textos para discussão em aulas.

A residência aumentou a prática científica o que facilitou o ingresso e a rotina de pesquisas, além de ter enriquecido as discussões durante as disciplinas. (R3)

A residência exerceu uma forte influência para eu cursar o mestrado, principalmente, por estimular a prática da pesquisa, que possibilita a consolidação da enfermagem como ciência, comprovando novos saberes, atualizando o conhecimento e respondendo a muitos questionamentos da nossa prática. (R4)

[...] a residência despertou o meu interesse em seguir a carreira docente, sendo que para isso, acredito que o mestrado seja essencial. (R4)

Evidencia-se nos relatos a importância do incentivo à produção cientifica para os entrevistados que entraram em programas de mestrado. A construção de novos conhecimentos se constitui como elemento importante para o desenvolvimento científico e tecnológico da enfermagem e da saúde, propiciado pelo avanço nas pesquisas na área e pela pós-graduação strictu sensu. Nesse contexto, verifica-se que após a especialização, grande parte dos profissionais de enfermagem tem optado por realizar cursos stricto sensu, que são de natureza acadêmica e de pesquisa a fim de se aprimorarem ainda mais a capacidade na produção científica iniciada na residência (FURUKAWA; CUNHA, 2011).

\section{Conclusão}

A residência em Gerência de Serviços de enfermagem proporcionou conhecimento e capacitação técnica para atuação dos enfermeiros na prática assistencial e incentivou o desenvolvimento de habilidades para produção científica, estimulando o aprimoramento profissional.

A residência em enfermagem foi considerada pelos enfermeiros uma transição da vida acadêmica para a atividade profissional, além disso, o mercado de trabalho atual, cada vez mais competitivo e com avançado desenvolvimento tecnológico, exige maior especialização. Aliado a isso, o respaldo dos docentes e enfermeiros dos campos de estágio proporciona uma maior segurança no desempenho das atividades gerenciais e assistenciais.

Portanto, a residência em enfermagem é considerada como um agente facilitador da passagem entre a universidade e o mercado de trabalho, pois o profissional é inserido de forma sutil devido à integração entre o meio acadêmico e o profissional.

Além disso, os egressos da residência em Gerência dos Serviços de Enfermagem da UEL sentiram-se melhor preparados tanto para atuar em serviços de saúde, devido à segurança no desempenho das suas atividades, como para ingressar em cursos de mestrado, pois a exigência da redação de artigos e o incentivo à pesquisa científica qualificam ainda mais este profissional.

A busca de discussão sobre o desenvolvimento dos cursos de residência deve ser constante, com o objetivo de avaliar os cursos de residência e principalmente verificar se os mesmos atendem as expectativas dos profissionais que ingressam nos programas, qualificando-os e tornando-os aptos para atender a demanda do mercado de trabalho.

\section{Referências}

BARDIN, L. Análise de conteúdo. Lisboa: Edições 70, 2011.

CARBOGIM, F. C.; SANTOS, K. B.; ALVES, M. S.; SILVA, G. A. Nursing residency: experience of Juiz de Fora from the point of view of residents. Revista APS: Atenção Primária a Saúde, Juiz de Fora, v. 13, n. 2, p. 245-249, abr.jun. 2010.

CONSELHO FEDERAL DE ENFERMAGEM COFEN. Resolução $n^{\circ}$. 259 de 12 de agosto de 2001. Dispõe sobre os padrões mínimos para registro do Enfermeiro Especialista, na modalidade de Residência em Enfermagem e dá outras providências. 2001. Disponível em: $<$ http://www.portal-cofen.com.br/ legislacao/resolucoes.htm>. Acesso em: 2 jun. 2011. 
FEUERWERKER, L. C. M.; CECÍLIO; L. C. O. O hospital e a formação em saúde: desafios atuais. Ciência \& Saúde Coletiva, Rio de Janeiro, v.12, n. 4, p. 965-971, jul./ago. 2007.

FURUKAWA, P. O.; CUNHA, I. C. K. O. Perfil e competências de gerentes de enfermagem de hospitais acreditados. Revista Latino-Americana de Enfermagem, Ribeirão Preto, v. 19, n. 1, p. 106114, jan./fev. 2011.

HADDAD, M. C. L. A residência de enfermagem na formação profissional. Ciência, Cuidado $e$ Saúde, Maringá, v. 11, n. 2, p. 225-225, 2012.

KIKUCHI, A. M.; GUARIENTE, M. H. D. M. Currículo integrado: a experiência do curso de enfermagem da Universidade Estadual de Londrina. Londrina: UEL, 2010.

MANZI, N. M.; REIS, P. E. D.; VASQUES, C. I.; CUSTÓDIO, C. S.; SIMINO, G. P. R.; BAMPI, L. N. S. A enfermagem como integrante da residência multiprofissional em um hospital universitário: relato de experiência. Revista de Enfermagem UFPE, Recife, v. 7, n. esp., p. 4281-4286, maio 2013.

MINETTO, R. C. Residência em enfermagem do Hospital de Base do Distrito Federal: avaliação dos ex-residentes. Comunicação em Ciências da Saúde, Brasília, v. 19, n. 2, p. 155-162, 2008.

PINHEIRO, J.; ZEITOUNE, R. C. G. O trabalho dos residentes de enfermagem na perspectiva dos riscos ocupacionais. HU Revista, Juiz de Fora, v. 37, n. 2, p. 225-232, abr./jun. 2011.

POLIT, D. F. BECK, C. T.; HUNGLER, B. P. Fundamentos de pesquisa em enfermagem. 7. ed. Porto Alegre: Artmed, 2011.

ROTHBARTH, S.; WOLFF, L. D. G.; PERES, A. M. O desenvolvimento de competências gerenciais do enfermeiro na perspectiva de docentes de disciplinas de administração aplicada à enfermagem. Texto \& Contexto-Enfermagem, Florianópolis, v. 18, n. 2, p. 321-329, abr./jun. 2009.
SANTOS, I.; CASTRO, C. B. Características pessoais e profissionais de enfermeiros com funções administrativas atuantes em um hospital universitário. Revista da Escola de Enfermagem da USP, São Paulo, v. 44, n. 1, p. 154-160, 2010.

SILVA, K. L.; SENA, R. R. Integralidade do cuidado na saúde: indicações a partir da formação do enfermeiro. Revista da Escola de Enfermagem da USP, São Paulo, v. 42, n. 1, p. 48-56, 2008.

SIMONETTI, S. H.; KOBAYASHI, R. M.; AYOUB, A. C.; LEITE, M. M. J. Perfil e expectativas dos ingressantes no curso de residência em enfermagem cardiovascular entre 1980 e 2004. Revista de Enfermagem da UERJ, Rio de Janeiro, v. 15, n. 3, p. 376-80, 2007.

UNIVERSIDADE ESTADUAL DE LONDRINA UEL. Departamento de Enfermagem. Residências em Enfermagem. Disponível em: $<$ http://www.uel. br/ccs/enfermagem/acessar.php/res.html>. Acesso em: 7 jul. 2014.

VANNUCHI, M.; CAMPOS, J. A metodologia ativa na residência em gerência do Curso de Enfermagem da UEL. Cogitare Enfermagem, Curitiba, v. 12, n. 3, p. 358-64, 2007. 